\title{
THE EFFECT OF TWO DIFFERENT IMPLANT ATTACHMENT JUNCTION DESIGNS ON MANDIBULAR KENNEDY CLASS (II) SUPPORTING STRUCTURES: A RADIOGRAPHIC EVALUATION
}

\author{
Mohamed Farouk Abdalla* and Ahmed Fahmy*
}

\begin{abstract}
Objective: This study was performed to evaluate the effects of a mandibular partial over denture supported by two different implant attachment designs on the supporting peri-implant bone.

Materials and methods: Fourteen patients were selected and divided into two groups; each group received one implant supported mandibular partial over denture in the distal extension area retained with ball and socket attachment. Group I: Received implants with conventional platform matching design (the abutment and implant of the same diameter) and Group II: Received implants with platform switched designs (the abutment is smaller in diameter than the implant). Radiographic evaluation was done using direct digital radiography. Bone density and bone loss measurements around implants were measured at denture insertion, 3 months, 6 months and 12 months intervals after partial over denture insertion.
\end{abstract}

Results: Mean percentage change was calculated followed by t-test for comparison between both groups, regarding bone height and density there was a statistically significant difference between the two implant designs for all the follow up periods with platform switched group (Group II) showing less values of bone loss, and better bone quality compared to the platform matching group (Group I).

Conclusion: The use of implants with a modified platform (platform switching) improved preservation of the crestal bone.

\section{INTRODUCTION}

Maintenance of marginal bone levels around dental implants have been a major topic of research since $1986^{1}$. When an implant is installed, normally, bone loss occurs around its neck. The literature contains numerous studies describing peri-implant marginal bone levels.

These studies typically report that crestal bone levels are 1.5 to $2.0 \mathrm{~mm}$ below the implantabutment junction (IAJ) at 1 year following implant

\footnotetext{
* Lecturer of Prosthodontics, Cairo University.
} 
restorations, which may also be dependent on the location of the IAJ relative to the bone ${ }^{2 \& 3}$.

Marginal crestal bone loss at implants is often attributed to a microbial effect ${ }^{4}$. The bacterial presence at the interface of implant-abutment junction seems to contaminate the micro-gap coronally, apically, and laterally for 0.5 to $0.6 \mathrm{~mm}^{5}$. Marginal bone loss around implants is also related to other parameters, such as periodontal biotypes ${ }^{6 \& 7}$, biological width formation ${ }^{3}$, and distance between implants ${ }^{8}$.

The concept of platform switching (PLS), introduced by Lazzara and Potter ${ }^{9}$ and Gardner ${ }^{10}$, suggested the use of an abutment or a supra-structure with a diameter at the implant-platform smaller than the implant diameter.

This configuration results in a circular horizontal step, which enables a horizontal extension of the biological width. The rationale for such platform switching is to locate the micro-gap of the implant abutment connection away from the vertical boneto-implant contact area. In another consensus some suggest that by narrowing the abutment further, the more the loading forces are favorably centered on the long axis of the implant.

Compared with a conventional restorative procedure using an identical size implant and suprastructure diameter, platform switching has been suggested to reduce or even prevent crestal bone loss. ${ }^{9-11}$

To date, the results of platform switching have been controversial, but most clinical studies have reported a positive impact of platform switching on crestal bone stability. The reduction in bone loss does appear to correlate with the size of the circular step.

Chang et al. compared the implant-bone interface stresses around PLS and matching implant, using 3D finite element analysis, they confirmed that the PLS design reduces the stress concentration in the area of compact bone and shifted it to the area of cancellous bone. ${ }^{12}$
In their systematic review focusing on the concept of platform switching Monje and Pommer concluded that, they generally favored platform switching over platform matching. ${ }^{13}$

In 2013 during the "Camlog Foundation Consensus" Schwarz .F. et al reported that regarding the position of the implant in the bone, placing the smooth part of the implant below the alveolar crest may lead to bone loss. And placing the rough surface of the implant subcrestal results in a more pronounced bone remodeling, however, the subcrestal positioning of the microgap may help to retain the bony coverage of the rough surface. Also crestal bone remodeling has been observed for either internal and external, or conical and buttjoint connections. And finally there was a trend favoring the platform switching concept to prevent or minimize peri- implant marginal bone loss. ${ }^{14}$

In a more recent study, in 2015 Joda et al conducted a cross-sectional study to estimate bone loss of implants with platform-switching design and analyze possible risk indicators after 5 years of loading in a multi-centered private practice network. The 5-year results of the study showed clinically acceptable values of mean bone loss after 5 years of loading. Implant-supported removable prostheses seem to be a strong co-factor for extensive bone level changes compared to fixed reconstructions. ${ }^{15}$

In the mean time partially edentulous arches that lack a distal tooth support, present many challenges to prosthodontists, these challenges are represented by lack of support, retention and the stabilization of the proposed prosthesis. Different solutions have been suggested to overcome challenges faced with distal extension cases, regarding change partial denture design, anterior placement of occlusal rest, types of clasps used, stress breaker system, the use of muco-functional impression technique and in unilateral cases, usage of cantilever design

One treatment option for suchclinical situations was suggested to solve the problem of distal extension cases, is the use of osseointegrated dental 
implants, thus converting the distal extension base removable partial denture from a tooth-tissue supported prosthesis with its problems into a toothimplant supported one. ${ }^{16 \& 17}$

Distal implants effectively convert a Kennedy Class I or II denture to a Kennedy Class III denture and increase the stability and retention of the prosthesis. Therefore, a tooth and implantsupported RPD is more economical (because fewer implants are needed) and more stable, and may therefore be a better option for patients with limited financial resources than a totally implant-supported, fixed restoration.

In this current radiographic study the amount and quality of bone around posterior implants with platform matching and platform switching designs will be observed, where these implants will support partial overdentures.

\section{MATERIAL AND METHODS}

Ten mandibular partially edentulous patients with Kennedy class II were selected, the criteria of selection included good oral hygiene and freedom from any systemic diseases that affect ossteointegration or bone resorption around the implant.

Patients were also radiographically diagnosed using Cone Beam Computed Tomography (CBCT) images, to evaluate bone volume (width and height) at the proposed implant site.

The selected cases were randomly divided into two equal groups;

Group I: Patients received a tooth-implant supported removable partial over-denture, after placement of platform matching conventional self threading implant (Simple Line, Dentium, Seoul, Korea) in the lower $1^{\text {st }}$ molar region, with ball and socket abutment as means of retention. In this group the implants were placed supra crestal, where the smooth implant collar was occlusal to the bone level. Fig (1-3)

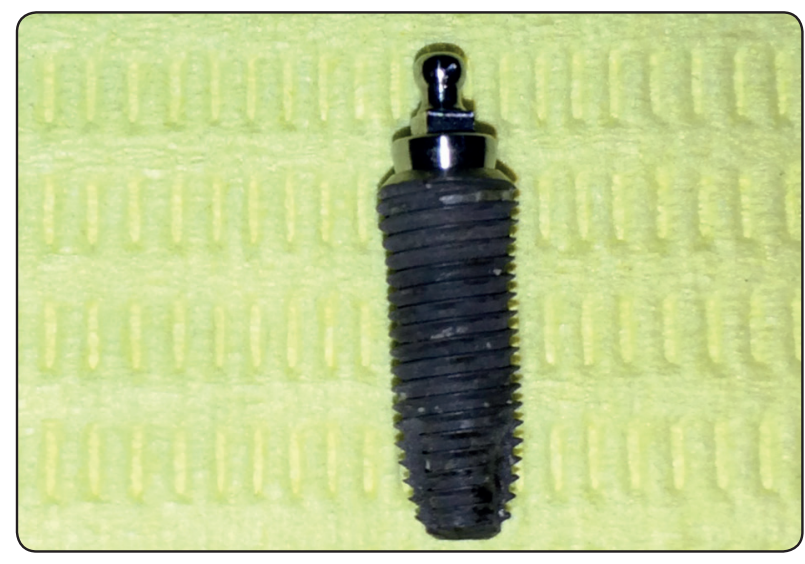

Fig. (1) Platform switching between the implant and the ball abutment.

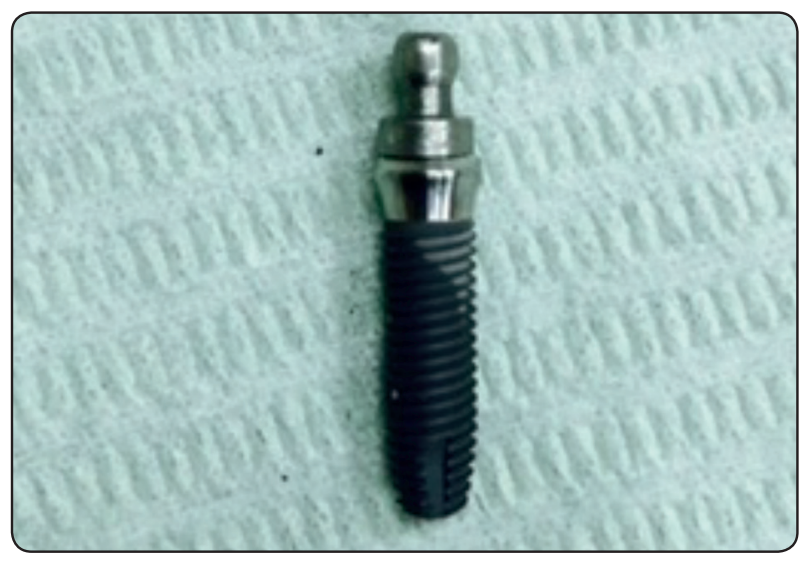

Fig. (2) Platform matching between the implant and the ball abutment.

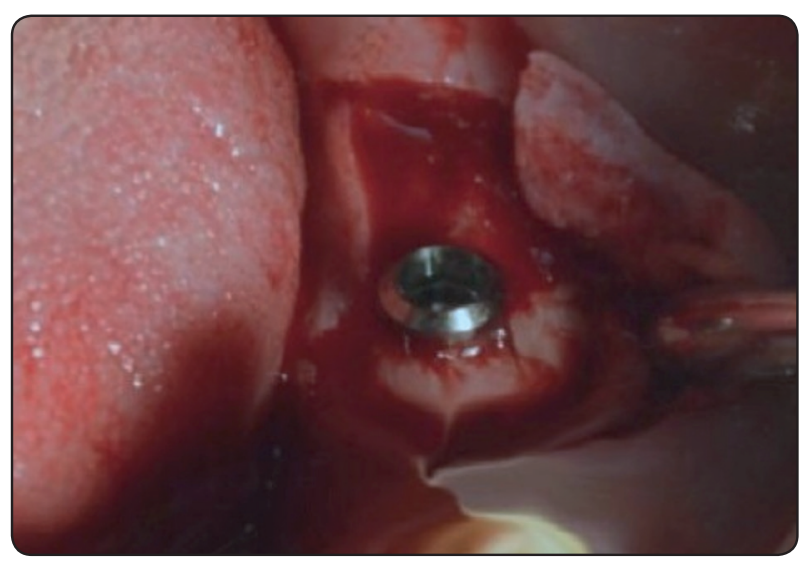

Fig. (3) implant placement in the molar area, supracrestal. 
Group II: Patients received a tooth-implant supported removable partial over-denture, after placement of platform switching self threading implant (Super Line, Dentium, Seoul, Korea) in the lower $1^{\text {st }}$ molar region, with ball and socket abutment as means of retention. In this group the implants' top were placed flushed with the bone.

Three months post implant insertion, the patients were recalled, the implants were uncovered and healing abutments were placed for 2 weeks.

The mucosal thickness was assessed using graduated periodontal probe so that the ball abutment with a proper collar height was chosen, and then the abutment was threaded into the implant, tightened followed bypartial denture construction .(figure 4)

\section{Partial denture design:}

The design for all finished partial denture was the same. Occlusal rests seats were prepared on the last standing natural teeth in form of mesial occlusal rest in lower first premolar. Direct retainer combination clasp was used in lower first premolar. Lingual bar major connector was used. And in the saddle area the meshwork was circumvented to accommodate the attachment. (fig, 5). Metal frameworks try in, followed by jaw relation and artificial teeth try, and denture processing was performed normally. fig (6). At time of delivery the adjustment of denture to accommodate super structure of implant by creating a hole in fitting surface of the acrylic denture at the area of the ball and socket. Direct pick-up for cap and housing assembly was done inside the patients' mouth. After setting of the acrylic resin, excess material was removed and then finishing and polishing were done.

\section{Follow up protocol:}

Using parallel cone technique and custom made film holders, standardized intra oral digital radiographs were used for the assessment of crestal bone level, and peri-implant bone quality surrounding the implants. The radiographs at 3,
6, 9 and 12 months were compared with base line radiographs. The marginal bone levels were assessed at mesial and distal side of the fixtures on the radiographs as well as bone density. Fig (7)

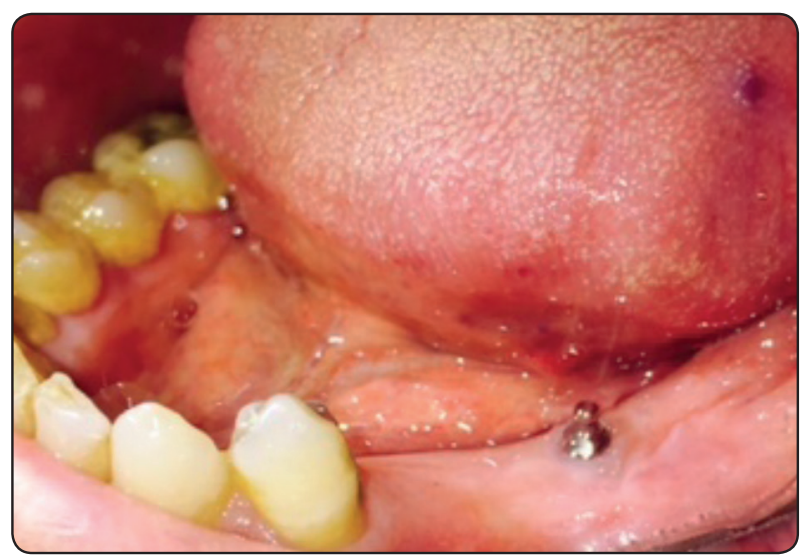

Fig. (4) Implant in the posterior area, with ball abutment.

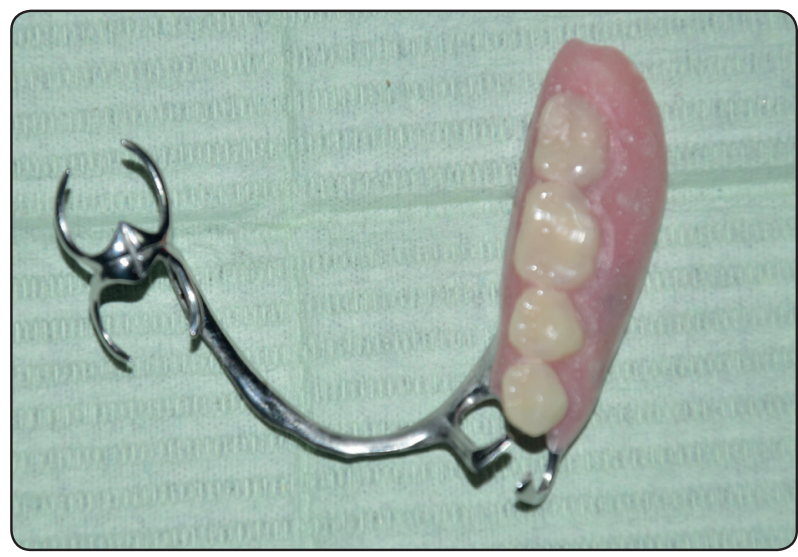

Fig. (5) Partial over denture.

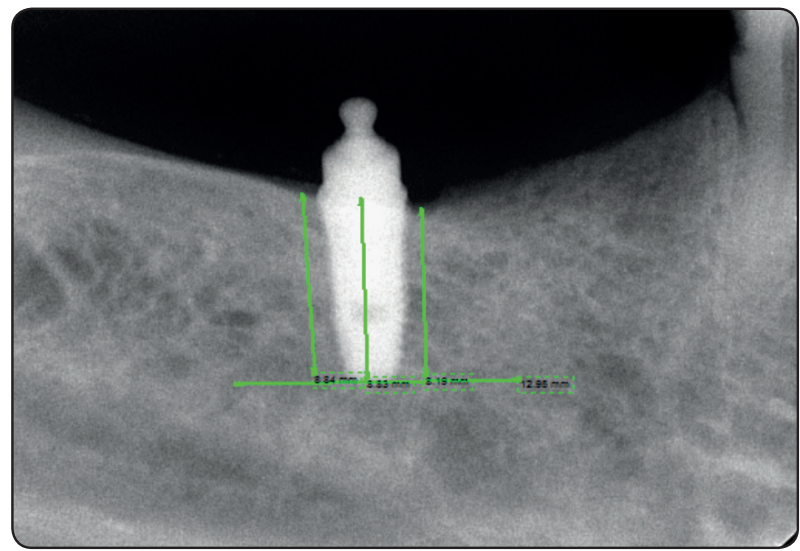

Fig. (6) Bone height measurements around platform switched assembly. 


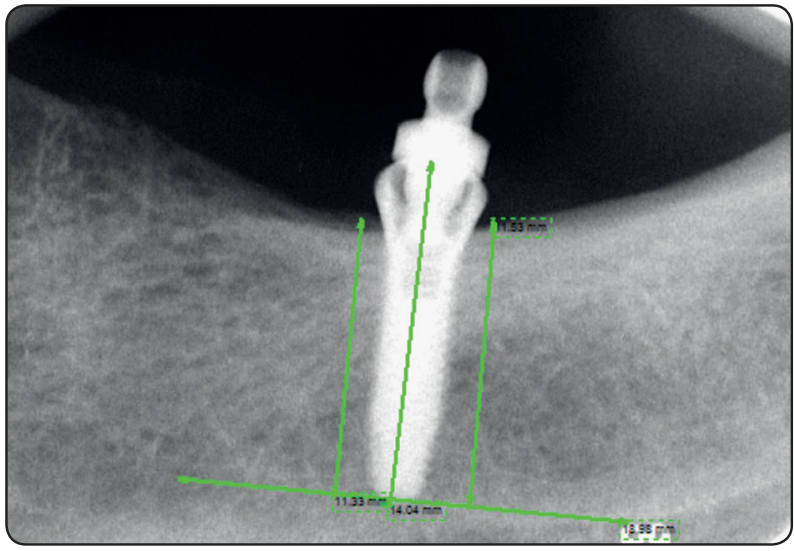

Fig. (7) Bone height measurements around platform switched assembly.

\section{RESULTS}

\section{Bone Density:}

This study was classified as case-control study and was performed to evaluate bone density and height around implant with ball and socket attachments during twelve months follow up period between platform switch and platform matching implants.

Measurements were taken mesially and distally to the implant and mean and standard deviation were calculated for further statistical study.

For more accurate significance, mean percentage change was calculated for both groups for each follow up interval using the following equation

\section{Bone density (Base line) - Bone density (Post-operative) $x 100$ \\ Bone density (Base line)}

Using $t$ test for comparison between both groups regarding bone density, there was insignificant difference between both groups at the baseline which indicated the absence of any bias during this study as ( $\mathrm{P}$ value $>0.05)$.

While during three, six, nine and twelve months follow up period, there was significant difference between both groups, where bone density was higher in the platform switch group, as listed in table (1) and showed in figure (8).
TABLE (1) Comparison between platform switching and platform matching during twelve months follow up period:

\begin{tabular}{|c|c|c|c|c|c|}
\hline \multirow{2}{*}{ Bone Density } & \multicolumn{2}{|c|}{$\begin{array}{c}\text { Platform } \\
\text { Switch }\end{array}$} & \multicolumn{2}{c|}{$\begin{array}{c}\text { Non-Platform } \\
\text { switch }\end{array}$} & \multirow{2}{*}{ P-value } \\
\cline { 2 - 5 } & Mean & SD & Mean & SD & \\
\hline Baseline & 165 & 14.73 & 163 & 11.40 & $0.73^{*}$ \\
\hline Three Months & 254 & 22.68 & 203 & 14.20 & $0.0001^{* *}$ \\
\hline Six Months & 281 & 25.09 & 228 & 15.94 & $0.0001^{* *}$ \\
\hline Nine Months & 307 & 27.41 & 278 & 19.44 & $0.0138^{* *}$ \\
\hline Twelve months & 321 & 28.66 & 293 & 20.49 & $0.0217^{* *}$ \\
\hline
\end{tabular}

M; Mean, SD; Standard deviation, P; Probability Level

*insignificant difference

**significant difference

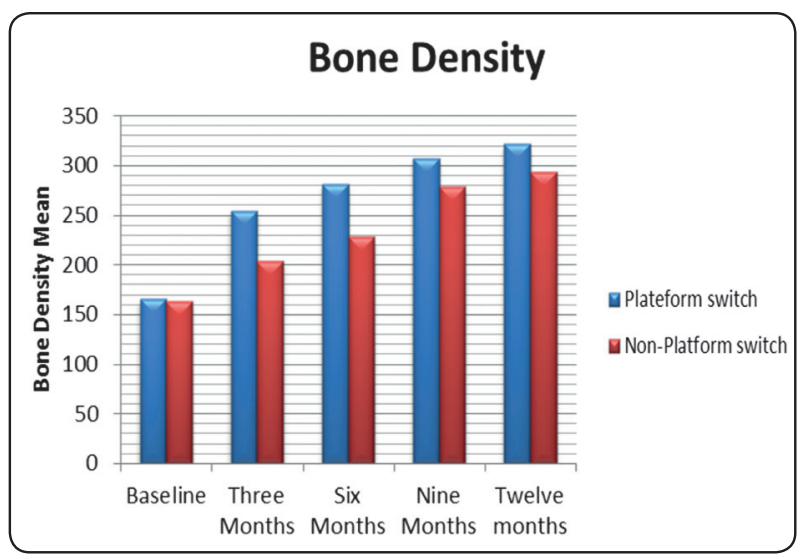

Fig. (8) Comparison between platform switching and platform matching, during twelve months follow up period.

After mean percentage change calculation, $t$ test was performed to calculate and significance between both groups which concluded that there was significant difference between both groups as (P-value < 0.05), listed in table (2) and showed in figure (9). 
TABLE (2) Mean percentage change for both groups for each interval:

\begin{tabular}{|c|c|c|c|c|c|}
\hline \multirow{2}{*}{ Bone Density } & \multicolumn{2}{|c|}{$\begin{array}{c}\text { Platform } \\
\text { Switch }\end{array}$} & \multicolumn{2}{c|}{$\begin{array}{c}\text { Non-Platform } \\
\text { switch }\end{array}$} & \multirow{2}{*}{ P-value } \\
\cline { 2 - 5 } & Mean \% & SD & Mean \% & SD & \\
\hline $\begin{array}{c}\text { Baseline- } \\
\text { three months }\end{array}$ & 53.94 & 7.95 & 24.54 & 2.8 & $0.0001^{* *}$ \\
\hline $\begin{array}{c}\text { Baseline-six } \\
\text { months }\end{array}$ & 70.3 & 10.36 & 39.88 & 4.54 & $0.0001^{* *}$ \\
\hline $\begin{array}{c}\text { Baseline_nine } \\
\text { months }\end{array}$ & 86.06 & 12.68 & 70.55 & 8.04 & $0.004^{* *}$ \\
\hline $\begin{array}{c}\text { Baseline_ } \\
\text { twelve months }\end{array}$ & 94.5 & 13.93 & 79.75 & 9.09 & $0.011^{* *}$ \\
\hline
\end{tabular}

M; Mean, SD; Standard deviation, P; Probability Level

**significant difference

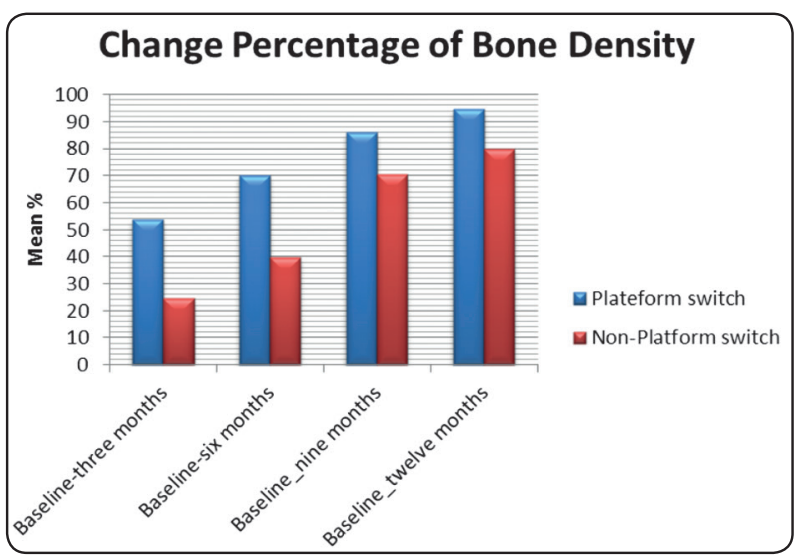

Fig. (9) Mean percentage change for both groups for each interval

\section{Bone Height:}

Measurements were taken mesially and distally to the implant and mean and standard deviation were calculated for further statistical study.

For more accurate significance, mean percentage change was calculated for both groups for each follow up interval using the following equation

Bone height (Base line)-Bone height (Post-operative) $\times 100$ Bone height (Base line)
Using t-test for comparison between both groups regarding bone height, there was insignificant difference between both groups at the baseline and after three months which indicated the absence of any bias during this study as ( $\mathrm{P}$ value $>0.05)$.

While during three, six, nine and twelve months follow up period, there was significant difference between both groups as listed in table (3) and showed in figure (10).

TABLE (3) Comparison between platform switching and platform matching during twelve months follow up period:

\begin{tabular}{|c|c|c|c|c|c|}
\hline \multirow{2}{*}{ Bone Height } & \multicolumn{2}{|c|}{$\begin{array}{c}\text { Platform } \\
\text { switch }\end{array}$} & \multicolumn{2}{c|}{$\begin{array}{c}\text { Non-Platform } \\
\text { switch }\end{array}$} & \multirow{2}{*}{ P-value } \\
\cline { 2 - 6 } & Mean & SD & Mean & SD & \\
\hline Baseline & 1.97 & 2.6 & 1.72 & 2.2 & $0.819^{*}$ \\
\hline Three Months & 2.05 & 0.09 & 2.02 & 0.04 & $0.348^{*}$ \\
\hline Six Months & 2.71 & 0.51 & 3.17 & 0.42 & $0.041^{* *}$ \\
\hline Nine Months & 3.07 & 0.8 & 4.1 & 0.3 & $0.0013^{* *}$ \\
\hline Twelve months & 3.67 & 0.75 & 4.45 & 0.42 & $0.0102^{* *}$ \\
\hline
\end{tabular}

M; Mean, SD; Standard deviation, P; Probability Level

*insignificant difference

**significant difference

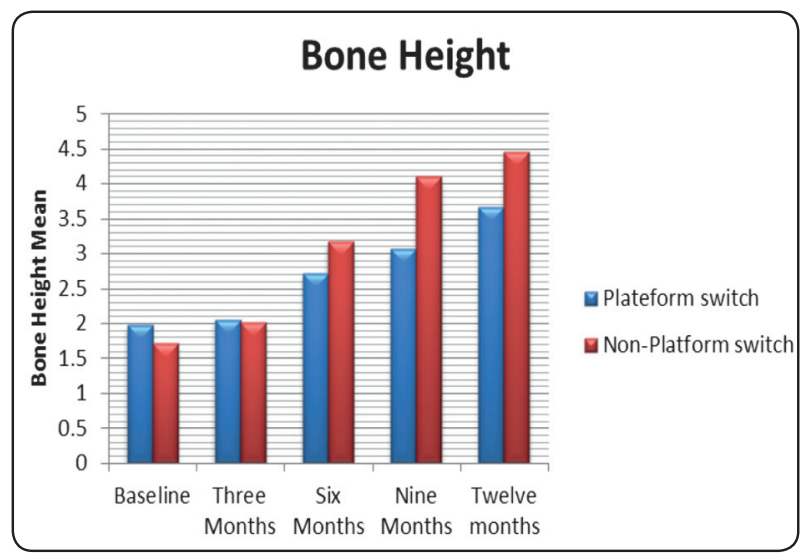

Fig. (10) Comparison between platform and platform matching, during twelve months follow up period 
After mean percentage change calculation, $\mathrm{t}$ test was performed to calculate and significance between both groups which concluded that there was significant difference, between both groups as (P-value < 0.05) where the platform switch group showed less percentage change, listed in table (4) and showed in figure (11).

TABLE (4) Mean change percentage for both groups for each interval:

\begin{tabular}{|c|c|c|c|c|c|}
\hline \multirow{2}{*}{ Bone Height } & \multicolumn{2}{|c|}{$\begin{array}{c}\text { Platform } \\
\text { switch }\end{array}$} & \multicolumn{2}{c|}{$\begin{array}{c}\text { Non-Platform } \\
\text { switch }\end{array}$} & \multirow{2}{*}{ P-value } \\
\cline { 2 - 5 } & Mean \% & SD & Mean \% & SD & \\
\hline $\begin{array}{c}\text { Baseline- } \\
\text { three months }\end{array}$ & 4.06 & 2.51 & 17.44 & 5.3 & $0.0001^{* *}$ \\
\hline $\begin{array}{c}\text { Baseline-six } \\
\text { months }\end{array}$ & 37.56 & 2.09 & 84.3 & 1.78 & $0.0001^{* *}$ \\
\hline $\begin{array}{c}\text { Baseline_- } \\
\text { nine months }\end{array}$ & 55.8 & 1.8 & 138.37 & 1.9 & $0.0001^{* *}$ \\
\hline $\begin{array}{c}\text { Baseline_ } \\
\text { twelve } \\
\text { months }\end{array}$ & 86.29 & 1.85 & 158.72 & 1.78 & $0.0001^{* *}$ \\
\hline
\end{tabular}

M; Mean, SD; Standard deviation,

P; Probability Level

**significant difference

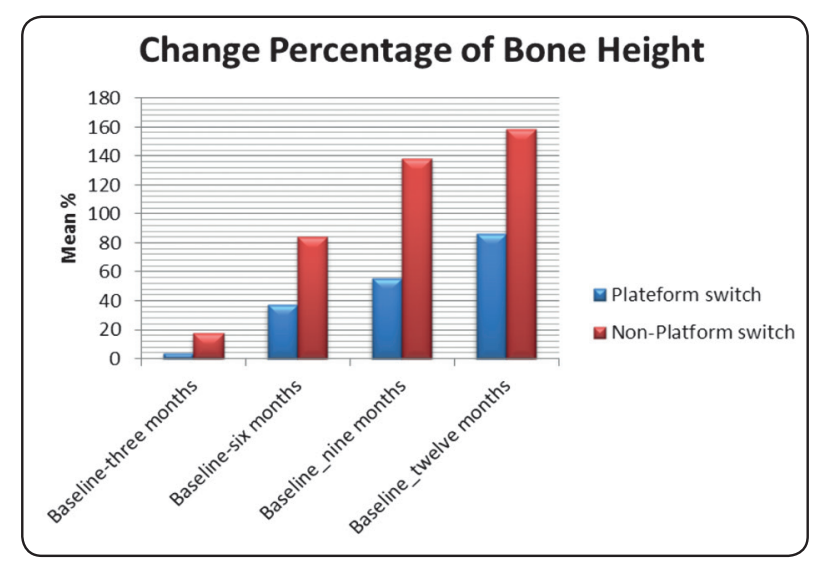

Fig. (11) Comparison between platform switching and platform matching during twelve months follow up period

\section{DISCUSSION}

It has been suggested that to overcome some of the problems associated with two-piece implants, the utilization of platform switching was indicated. Platform switching may increase the distance between the abutment-associated inflammatory cell infiltrate and the marginal bone level, and thereby decrease its bone-resorptive effect. ${ }^{18}$

The reasons for the reduced bone loss and better bone quality observed in platform- switched implants in the present study can only be explained by, the horizontal inward re-positioning of the implant-abutment interface

Another possible reason for better bone quality and less bone loss present with platform switching implants, was the presence of micro- threads in the marginal portion of the implants. The possible influence of such a design on the marginal bone loss was that the marginal bone level was located at a more coronal position as related to the implants. Where in conventional implants design with smooth collar the marginal bone was located apically. It has been suggested that these possible positive effects may be related to the osseous healing events after implant placement rather than bone preservation during function. ${ }^{19-25}$

\section{CONCLUSION}

It was concluded that platform switching is capable of reducing the amount of crestal bone loss. The use of implants with a modified platform (platform switching) improves preservation of the crestal bone.

\section{REFERENCES}

1. Albrektsson T, Zarb G, Worthington P, Eriksson AR. The long-term efficacy of currently used dental implants: A review and proposed criteria for success. Int J Oral Maxillofac. Implants 1986;1:11-25.

2. Hermann JS, Cochran DL, Nummikoski W, Buser D. Crestal bone changes around titanium implants. A radiographic evaluation of unloaded nonsubmerged and submerged implants in the canine mandible. J Periodontol 1997;68:1117-1130. 
3. Hermann JS, Buser D, Schenk RK, Schoolfield JD, Cochran DL. Biologic Width around one- and two-piece titanium implants. Clin Oral Implants Res 2001;12:559-571.

4. Lindhe J, Meyle J. Group D of European Workshop on Periodontology. Peri-implant diseases: Consensus Report of the Sixth European Workshop on Periodontology. J Clin Periodontol 2008 Sep; 35(8 Suppl):282-285.

5. Ericsson I, Persson LG, Berglundh T, Marinello CP, Lindhe J, Klinge B. Different types of inflammatory reactions in periimplant soft tissues. J Clin Periodontol 1995; 22: 255-261.

6. Linkevicius T, Apse P, Grybauskas S, Puisys A. The influence of soft tissue thickness on crestal bone changes around implants: a 1-year prospective controlled clinical trial. Int J Oral Maxillofac Implants 2009;24:712-719.

7. Linkevicius T, Apse P, Grybauskas S, Puisys A. Influence of thin mucosal tissues on crestal bone stability around implants with platform switching: a 1-year pilot study. J Oral Maxillofac Surg 2010;68:2272-2277.

8. Rodriguez-Ciurana X, Vela-Nebot X, Segala-Torres M, Rodado-Alonso C, Mendez-Blanco V, Mata-Bugueroles M. Biomechanical repercussions of bone resorption related to biologic width: a finite element analysis of three implantabutment configurations. Int J Periodont Restorative Dent 2009;29:479-487.

9. Lazzara RJ, Porter SS. Platform switching: a new concept in implant dentistry for controlling postrestorative crestal bone levels. Int J Periodontics Restorative Dent 2006; 26:9-17.

10. Gardner DM. Platform switching as a means to achieving implant esthetics. N Y State Dent J 2005;71:34-37.

11. Broggini N, McManus LM, Hermann JS, Medina R, Schenk RK, Buser D, Cochran DL. Peri-implant inflammation defined by the implant-abutment interface. J Dent Res 2006;85:473-478.

12. Chang, C. L., Chen, C.S. \& Hsu, M.L. : Biomechanical effect of platform switching in implant dentistry: a threedimensional finite element analysis. The Intern J. of Oral \&MaxillofacImpl 2010, 25, 295-304.

13. The Concept of Platform Switching to Preserve Periimplant Bone Level: Assessment of Methodologic Quality of Systematic Reviews Int J Oral Maxillofac Implants 2015; 30:1084-1092.

14. Schwarz F, AlcoforadoG, Nelson K, Schaer A, Taylor T, Beuer F, Strietzel FP. Impact of implant-abutment connection, positioning of the machined collar/microgap, and platform switching on crestal bone level changes . Camlog Foundation Consensus Report. Clin.Oral Impl. Res. 25, 2014, 1301-1303.
15. Tim Joda,Ioanna Michelaki, Guido Heydecke Peri-implant bone loss of dental implants with platform-switching design after 5 years of loading: A cross-sectional study. Quintessence Int2015;46:59-66;

16. Carpenter JF. Implant-assisted unilateral removable partial dentures.Dent Today. 2014; 33 (1): 106.

17. Gharehchahi J, Asadzadeh N, Mirmortazavi A, Shakeri MT. : Maximum dislodging forces of mandibular implantassisted removable partial dentures: in vitro assessment. J Prosthodont.2013;22(7):543-9.

18. Cacilda Cunha Ferraz , R.B.A., Erika Oliveira de Almeida; AmilcarChagasFreitasJu ńior, F. b. C. F., Lucas Silveira Machado, Rocha, E. P.: Influence of microthreads and platform switching on stress distribution in bone using angled abutments. Journal of prosthodontic research 2012, 149.

19. Luongo, R.; Traini, T.; Guidone, P. C.; Bianco, G.; Cocchetto, R.; Celletti, R.: Hard and soft tissue responses to the platform-switching technique. The International journal of periodontics \& restorative dentistry 2008, 28, 551-7.

20. Gutlapalli, N. J.; Reddy, D. M.; Mikkilineni, H.: Implantsupported overdentures. Journal of the New Jersey Dental Association 2013, 84, 2

21. Cacilda Cunha Ferraz, R. B. A., Erika Oliveira de Almeida,; Amilcar Chagas Freitas Ju'nior , F. b. C. F., Lucas Silveira Machado ; Rocha, E. P.: Influence of microthreads and platform switching on stressdistribution in bone using angled abutments. Journal of prosthodontic research 2012, 149.

22. Canullo, L.; Pellegrini, G.; Allievi, C.; Trombelli, L.; Annibali, S.; Dellavia, C.: Soft tissues around long-term platform switching implant restorations: a histological human evaluation. Preliminary results. Journal of clinical periodontology 2011, 38, 86-94.

23. Al-Nsour M, Chan H, Wang H. Effect of the platformswitching technique on preservation of peri-implant marginal bone: A systematic review. Int J Oral Maxillofac Implants 2012;27:138-145.

24. Zuiderveld. E, Hartog.L, Vissink.A, Raghoebar.G, Meijer.H . Significance of Buccopalatal Implant Position, Biotype, Platform Switching, and Pre-implant Bone Augmentation on the Level of the Midbuccal Mucosa. Int J Prosthodont 2014;27:477-479.

25. Canullo, L.; Pellegrini, G.; Allievi, C.; Trombelli, L.; Annibali, S.; Dellavia, C.: Soft tissues around long-term platform switching implant restorations: a histological human evaluation. Preliminary results. Journal of clinical periodontology 2011, 38, 86-94. 